\title{
Interchange Fees as a Mechanism to Raise Rivals' Costs - Some Evidence from Switzerland
}

SAMuel Rutz

JEL-Classification: L4, G2

Keywords: antitrust, payment systems, interchange fees, two-sided markets

\section{Introduction}

Payment card schemes typically involve a number of institutions that process payments as intermediaries between merchants and cardholders. In such schemes the acquiring of merchants and the issuing of payment cards is typically separated: merchants contract with an external company that "acquires" the transaction while payment cards are issued to consumers by their house bank or a specialized card issuer. Due to the four parties involved (acquirer, merchant, issuer and cardholder) such a system is often called a "four-party" system. The value of a four-party system depends crucially on the acceptance of a certain payment card by the acquirer (or the merchant) independent of the issuer of the card. One possible way to organize a four-party system is therefore that each acquirer and issuer negotiate bilateral conditions of acceptance of a certain payment card. Another solution, which is far more common, is to form a joint venture that sets a number of system-wide rules. Such a solution involves setting up a payment platform such as MasterCard or Visa. On the one hand these platforms help to minimize transaction costs that may arise through bilateral contracting. However, on the other hand they may lead to coordination over key business practices, such as pricing conditions, the no-surcharge rule or the honor-all-cards rule. ${ }^{1}$

a Chief Economist of the Secretariat of the Swiss Competition Commission, CH-3003 Berne. Email: samuel.rutz@weko.admin.ch. All views contained in this text are solely those of the author and cannot be attributed to the Swiss Competition Commission or its Secretariat. The author would like to thank Martin Brown, Stefan Bühler and Sarah Rivière for helpful comments.

1 The no-surcharge rule prohibits merchants who accept credit cards from imposing a surcharge on customers who pay by credit card or allowing a discount in return for payment in cash or other means of payment. In contrast, the honor-all-cards rule requires the merchant to accept all cards (e.g. debit and credit cards) from a certain payment card scheme. 
The interchange fee, a fee which is paid for each credit card transaction by the acquirer to the issuer, has attracted considerable attention in the antitrust and the academic community. ${ }^{2}$ In practice there are two different types of interchange fees in place: domestic and cross-border interchange fees. Domestic interchange fees apply to all transactions involving a credit card issued in a specific country at a point of sale in the same country. In contrast, cross-border interchange fees apply to all non-domestic transactions and are set by the credit card schemes (e.g. MasterCard or Visa). In many countries the domestic interchange fees are negotiated and fixed multilaterally in national card committees in which both issuers and acquirers are represented. Competition authorities in many countries are therefore concerned about harmful price-fixing agreements among competitors.

Many academics argue that multilateral agreed interchange fees are sensible and necessary since credit card systems are fundamentally two-sided markets (see e.g. Rochet and Tirole, 2003): one side of the market consists of the acquiring business where for each processed credit card transaction the merchant pays a certain percentage of the purchase price to his acquirer in the form of the merchant service charge. The other side of the market consists of the issuing business where the cardholders pay various fees, such as annual fees, fees for partner cards, credit interest and foreign exchange commissions, to the issuer involved. The key aspect of such a two-sided market is to balance demand on the two sides of the market in such a way that an optimal number of merchants and cardholders join the payment platform. According to this view, the interchange fee is an indirect instrument to influence end-user prices and consequently demand in the acquiring and the issuing business. This instrument is necessary in a four-party system since there is no single owner of the platform who could directly set optimal end-user prices. Abolishing or regulating interchange fees in such systems may therefore deprive the members of the platform of the ability to perform the balancing act. It is thus argued that even if multilateral agreed interchange fees are not in any case set automatically at a social optimal level, there is not per se a case for an intervention by competition authorities, since this might in effect worsen the situation.

In 2004, the Swiss Competition Commission (ComCo) opened an investigation concerning the interchange fees of Visa and MasterCard in the Swiss credit card market which ended with an amicable settlement between the parties and

2 For a comprehensive and non-technical discussion of the economics of interchange fees see e.g. Hunt (2003), Klein, Lerner, Murphy and Plache (2006) or Frankel and Shampine (2006). 
ComCo in $2005 .^{3}$ The most important element of this amicable settlement consists in the limitation of the interchange fee to the actual network costs of the issuers. According to Rochet and Tirole (2003), such a public intervention is however only justified if the two following conditions are satisfied: (1) there is a serious market failure with empirical relevance; (2) the chosen remedy is the least distortionary way of addressing the market failure and is not worse than the illness. In this paper I address the questions as to whether there was indeed a market failure in the Swiss credit card market which justified an intervention by ComCo and whether the remedies imposed in the amicable settlement eliminated the alleged market failure.

To this purpose I first show that a market failure in the Swiss credit card industry, in the sense of multilateral agreed interchange fees being harmful to effective competition, is plausible. In particular, I argue that there is the possibility that interchange fees were not used to balance the two sides of the market: my analysis suggests that changes in the interchange fee did not, in the past, affect prices in the issuing and the acquiring market as predicted by the theory of twosided markets. This result may be linked to the fact that in the literature it is usually assumed that the service providers on the two sides of the market are structurally independent, an assumption which is often violated in payment card schemes (i.e. issuers and acquirers are owned by the same proprietors). In such a situation the multilateral fixing of interchange fees may well produce anti-competitive effects. The findings for Switzerland suggest that national card committees used the interchange fee primarily to deter entry in the acquiring market by raising rivals' costs.

In a second step the effects of the amicable settlement in the Swiss credit card market are evaluated. As the developments in the credit card industry show, it seems safe to conclude that so far the imposed remedies did not worsen the situation. Several indicators (such as an increasing number of issued credit cards, an increasing transaction volume, decreasing prices for cardholders and merchants and a range of new credit card products) point to revived competition in the credit card market.

The paper is structured as follows: section 2 provides a short introduction to the theory of two-sided markets. Section 3 provides an overview of the recent developments in the Swiss credit card market. In section 4 a simple model of a two-sided market for the determination of the optimal interchange fee and prices

3 The subject matter of an amicable settlement are the measures that eliminate a probable restraint of competition under the Swiss Cartel Act. 
in a payment card system is presented and it is discussed whether the observed developments in the Swiss credit card market are consistent with this model. Section 5 presents an alternative explanation for the observed developments in the Swiss credit card market which point to anti-competitive effects of the multilateral fixing of interchange fees. Section 6 discusses the case of ComCo regarding the multilateral fixing of interchange fees and the effects of the amicable settlement. Section 7 concludes.

\section{Two-Sided Markets and Interchange Fees}

In recent years a growing literature on two-sided markets emerged. ${ }^{4}$ Following Rochet and Tirole (2004a, 2004b) a two-sided market can roughly be defined as a market in which one or several platforms enable interaction between endusers, and attempt to get the two sides "on board" by appropriately charging each side. Three elements are usually listed that characterize a two-sided market: (1) there are two distinct groups of end-users which jointly use an end product offered via a platform; (2) there are externalities which cannot be internalized without the platform; (3) by differentiating end-user prices the demanded quantities of the two end-user groups can be optimized, i.e. the externalities can be internalized. ${ }^{5}$ Besides payment card systems, often cited examples of two-sided markets include video-game platforms, software production, internet portals, TV networks or newspapers. ${ }^{6}$

Two-sided markets are typically characterized by two types of externalities: usage and membership externalities. In a four-party payment card system, for example, the usage externality simply stems from the usage decision of the cardholder. It refers to the fact that consumers choose the form of payment while the merchant bears the resulting direct costs that may vary with different means of payments as e.g. cash, credit and debit cards, cheques etc. The membership externality reflects the fact that an end-user on one side of the market derives a strictly positive net surplus from interacting with additional end-users on the other side of the market. This means that for consumers it becomes increasingly

4 For an introduction and overview see e.g. Rochet and Tirole (2004a, 2004b) or Roson (2005).

5 Rochet and Tirole (2004a, 2004b) refine this condition to the effect that the aggregate demand on the platform can be influenced by adjusting end-user specific prices while keeping the aggregate price level constant.

6 For further and more detailed examples see e.g. Evans (2003). 
attractive to hold a specific payment card the wider the card is accepted by merchants. By the same token it gets increasingly attractive for merchants to accept a certain payment card the higher the number of cardholders.

The fact that in four-party payment card systems there is no single owner of the platform, who could directly set optimal end-user prices to internalize usage and membership externalities, is commonly used to justify the existence of interchange fees between acquirers and issuers. The first economic defence of interchange fees along these lines goes back to BAXTER (1983) who focuses in his analysis on usage externalities. ${ }^{7}$ Baxter assumes that income from cardholders is too small for the average issuer to cover its costs, whereas income from merchants is on average more than sufficient for acquirers to cover their costs. The interchange fee remedies this imbalance by subsidizing the issuing business. Without this remedy it is even possible that consumers refuse to hold and use payment cards even though the aggregate benefits of the cardholders and merchants exceeds the aggregate costs of the issuers and acquirers. ${ }^{8}$

Based on Baxter's analysis, a growing number of models aimed at determining the optimal price structure and interchange fee in payment card systems and identifying welfare effects of different interchange fees under the assumption of price coherence have emerged. ' Schmalensee (2002) for example relaxes the assumptions of a perfectly competitive issuing and acquiring market and homogenous merchants. Rochet and Tirole (2002) assume in their model an imperfect issuing market and account for the possibility of business stealing, i.e. accepting payment cards for the strategic reason of attracting customers from merchants who do not accept cards. WRIGHT (2004a) generalizes these two models by introducing imperfect competition on the issuing and acquiring market, heterogeneous cardholders and merchants and business stealing.

The results from the above mentioned models suggest that several factors influence the pricing policy and consequently the setting of the interchange

7 Most of the literature focuses primarily on usage externalities since it is argued that membership externalities become less and less important as a payment card system matures, i.e. when virtually all potential users have joined the payment card system (see e.g. Rochet and Tirole, 2003).

8 Several authors (see e.g. Carlton and Frankel, 1995; Katz, 2001; Gans and King, 2001; WRIGHT, 2003) have pointed to a conceptual flaw in Baxter's analysis: there is a different method to internalize the usage externality in Baxter's model, namely to allow merchants to charge differentiated prices for different means of payment. However, it seems widely accepted in the literature that there is a certain price coherence which tends to persist, i.e. price differentiation by means of payments is not very common. Thus, as long as the better part of the merchants cannot or is not willing to differentiate prices, the usage externality will prevail.

9 For an overview of recent contributions see e.g. Rochet (2003) or Chakravorti (2003). 
fee. ${ }^{10}$ These factors are the demand elasticities on the two sides of the market, the market power of the service providers and the surplus created on the two sides of the market. Other factors such as platform competition and multi-homing ${ }^{11}$ or product bundling can as well have an influence on end-user prices. Further, the results suggest that it cannot be concluded that platforms do have an incentive to set the socially optimal interchange fee. However, theory seems unable to answer the question whether platforms will set the interchange fee systematically too high or too low compared to the social optimum.

The definition of two-sided markets implies a common assumption in all of the above discussed models, namely the balancing effect of the interchange fee. The mechanism can intuitively be described as follows: an increase of the interchange fee raises the revenues of the issuers. This can be thought of as a subsidy to the issuer which allows for lower cardholder fees and consequently leads to an increase in demand for this payment card. On the acquiring side, an increase in the interchange fee lowers revenues. Acquirers will therefore have to raise the merchant service charge to compensate for the lost revenues which lowers the acceptance of payment cards in the system. However, the increased demand for credit cards may render the acceptance of credit cards more attractive for merchants and offset the latter effect. Of course, a reduction in the interchange fee will have the opposite effect.

In what follows, the balancing effect of the interchange fee will be studied in more detail. First, some details about the developments in the in the Swiss credit card market, in particular about changes in the interchange fee and prices in the acquiring and issuing market, will be provided. Then, a simple model is developed to check whether the observed developments in the Swiss credit card market are consistent with the alleged balancing function of the interchange fee.

\section{Interchange Fees and Prices in the Swiss Credit Card Market}

As noted in the introduction, at the end of 2005 the Swiss issuers and acquirers signed an amicable settlement with the Swiss Competition Commission (ComCo) which limits the level of the domestic interchange fee to the effective network costs of the issuers. In other words, since then a restriction is in place

10 For the logic of price-setting in two-sided markets see as well Wright (2004b).

11 Because the different payment card systems are normally not interconnected, merchants usually accept and consumers often hold more than one payment card. This behaviour is called multi-homing. 
which may impair the balancing function of the interchange fee in the Swiss credit card market. Therefore, only the period 2000-2005 will be considered in what follows.

Four credit card schemes (Visa, MasterCard, American Express and Diners Club) traditionally operate in Switzerland. Visa and MasterCard are organized as four-party systems, whereas American Express and Diners Club operate as so-called three-party or proprietary systems. ${ }^{12} \mathrm{JCB}$ cards - another global proprietary system - are accepted by relatively few merchants and are not issued in Switzerland. With a combined market share of $85 \%-95 \%$, MasterCard and Visa are historically by far the most important players in the credit card industry. ${ }^{13}$ Considering the market share of $0 \%-10 \%$ and the relative small acceptance of American Express and Diners Club they can be considered as niche players in Switzerland.

Since 1998 all issuers and acquirers of Visa and MasterCard cards offer and process both brands (so-called "dual branding"). Further, the products of Visa and MasterCard are widely standardized and there are neither for the issuers nor for the acquirers significant differences in the costs and benefits the two brands generate. In fact, the two brands are regularly processed on the same systems. As a consequence, there are no incentives for the issuers and acquirers to favor one brand over the other, i.e. competition between the two brands on the issuing and the acquiring level is more or less non-existent. This is also reflected in the range of offered credit card products and their terms and conditions. The most prevalent credit card products offered by the issuers are the standard and the gold card which are available from Visa and MasterCard. Furthermore, as discussed in section 3.2 below, the issuers do not price discriminate between the card products of the two brands. In the acquiring business most of the merchant contracts today contain so-called "blended rates", i.e. the merchant service charge is not differentiated with respect to the card brand involved in the transaction. The two brands will therefore not be treated separately in the following sections.

12 In a three-party or proprietary system, the acquiring and the issuing are carried out by the same company. End-user prices can therefore directly be set by the platform, i.e. there is no need to set an interchange fee.

13 All figures, i.e. market shares, prices in the acquiring and issuing market and their development etc., can be found in the decision "Kreditkarten - Interchange Fee" of the Swiss Competition Commission (СомСо, 2006). Since the exact value of the figures constitute business secretes, they can only be provided in ranges. 


\subsection{Acquiring Market}

Until the middle of 2003 three domestic companies were operating in the Swiss acquiring market: Telekurs Multipay ${ }^{14}$, UBS Card Center and Cornèr Banca. In May 2003 UBS Card Center sold its acquiring business to Telekurs Multipay, reducing the number of domestic actors in the market to two. Further, in July 2005, Aduno assumed the acquiring business of Cornèr Banca. At the end of 2005 there existed consequently two domestic acquirers for Visa and MasterCard, Telekurs Multipay and Aduno, both "dual branding".

Table 1: Market Shares of Visa and MasterCard Acquirers

\begin{tabular}{lc}
\hline Acquirer & Market Shares 2003 (Visa \& MasterCard) \\
\hline Telekurs Multipay & $70 \%-80 \%$ \\
Cornèr Banca & $20 \%-30 \%$ \\
B\&S Card Service, Concardis & $0 \%-5 \%$ \\
\hline
\end{tabular}

Source: СомСo (2006)

Besides these two domestic acquirers, there are approximately ten foreign acquirers operating in Switzerland. Most of these companies do however not actively acquire merchants. So far they have mainly concluded contracts with a few multinational companies having subsidiaries in Switzerland (e.g. airlines). In the last few years the two German acquirers B\&S Card Service and ConCardis started with modest success to actively acquire merchants. As can be seen in Table 1, their market share in 2003 was still rather small. In contrast, Telekurs Multipay, being the dominant player in the market, held a market share of $70 \%-80 \%$. The market entry of the two German acquirers caused a certain downward pressure on the average merchant service charge which fell from roughly $2.5 \%$ to $2.3 \%$ in the considered period.

14 Telekurs Multipay is a joint venture owned by the Swiss banks, including three out of the four domestic issuers. 


\subsection{Issuing Market}

In 2003 four domestic companies were active in the market for the issuing of Visa and MasterCard credit cards: Cornèr Banca, Credit Suisse, Viseca ${ }^{15}$ and UBS. All of them issued both brands of credit cards. The respective market shares of the four issuers in 2003 can be found in Table 2. These market shares remained basically constant over the considered five years and the market is characterized by a relatively strong concentration with a $H H I$-coefficient of more than 2800 . New market entries were not observed in the considered period.

Table 2: Market Shares of Visa and MasterCard Issuers

\begin{tabular}{lc}
\hline Issuer & Market Shares 2003 (Visa \& MasterCard) \\
\hline UBS & $30 \%-40 \%$ \\
Viseca & $20 \%-30 \%$ \\
Credit Suisse & $20 \%-30 \%$ \\
Cornèr Banca/Aduno & $10 \%-20 \%$ \\
\hline
\end{tabular}

Source: ComCo (2006)

The annual cardholder fees in Switzerland, in particular in comparison with other EU countries, seemed very high at the time (roughly 2.5 times higher than the EU average). Such direct price comparisons are however to be treated with caution. First, they do not account for possible perquisites and rebates. Second, the conditions in the credit card business can vary substantially across countries. The option for revolving credits for example is only reluctantly used in Switzerland, reducing potential revenues from interest payments for the issuers.

Nevertheless, official list prices can provide an indication for the degree of price competition in a market. These list prices for different brands and types of credit cards remained remarkably constant in the last decade. For a Visa or MasterCard standard credit card for example all four issuers charged more or less uniformly CHF 100 since 1997. The few price alignments occurring for other credit card products in recent years were price increases leading to an equalization of list prices. It is further interesting to note that in the same period the number of issued credit cards increased by nearly $30 \%$.

15 Viseca is a joint venture of several smaller Swiss banks (cantonal banks, Raiffeisen Group, RBA Banks, Migrosbank, Bank Coop and several private and merchant banks). 
An analysis of the average net earnings per credit card reveals a constant increase in overall card fees, resulting in a substantial increase of average industry profit. Thereby, the net earnings of the issuers are defined as total earnings from annual fees, interest payments and other credit card related services (e.g. commissions from cash withdrawals or foreign currency conversion fees) minus total industry costs for rebates and perquisites. Note that earnings from interchange fees are not included in the calculation. The average net earnings per credit card are then calculated by dividing the net earnings of the issuers by the number of issued credit cards. A refined analysis shows that the average annual fee for a credit card in Switzerland increased between 2000 and 2003 from roughly CHF 60 to over CHF 70. During the same period interest earnings per credit card increased from ca. CHF 34 to CHF 45. Finally, other credit card related earnings increased from roughly CHF 56 to nearly CHF 74. Taken together, this resulted in an average increase of overall card fees of 26\% between 2000 and 2003. Even when excluding from the analysis the interest earnings per credit card, which primarily depend on the decision of the consumers to use their credit option, the increase of average credit card fees still amounted to $24 \%$.

\subsection{Average Domestic Interchange Fee}

The domestic interchange fee is not a single value in practice. Rather there is a system of interchange fees, differentiated with regard to transaction types (e.g. chip based vs. enhanced electronic transactions) and industry sectors (e.g. supermarkets vs. airlines). In the first half of the considered period MasterCard increased its interchange fee for standard transactions, which applies to roughly $25 \%$ of the transaction volume, to $1.8 \% .^{16}$ This caused an increase of the average domestic interchange fee (DMIF), where the DMIF is simply calculated by weighting the differentiated interchange fees by their respective transaction volume.

While the effect of the increase of the interchange fee for standard MasterCard transactions on the DMIF was modest in absolute terms, the financial consequences for the issuers are considerable. To see this, note that the total credit card transaction volume in Switzerland in 2003 amounted to CHF 15 billion. The information indicating which fraction of these CHF 15 billion was generated with credit cards issued in Switzerland (to which the DMIF applies) is

16 The exact increase of the standard interchange fee cannot be reported since it constitutes a business secret of MasterCard. 
unfortunately not available. Assuming however that a quarter of all transactions involved a foreign credit card, the domestic total credit card transaction volume in 2003 amounted to CHF 11.3 billion. Roughly half of this transaction volume (CHF 5.6 billion) can be attributed to MasterCard. The increase in the standard interchange fee applied to roughly $25 \%$ of this transaction volume, i.e. to CHF 1.4 billion. Every increase in the standard interchange fee of $0.1 \%$ consequently generates an additional CHF 1.4 million for the issuers per year. With an increasing total credit card transaction volume over time, these additional earnings obviously increase proportionally. In 2007 for example the total transaction volume already amounted to CHF 20 billion and an increase in MasterCard's standard interchange fee of $0.1 \%$ was worth CHF 1.9 million.

\section{The Balancing Effect of the Interchange Fee}

To analyse the question whether the developments in the Swiss credit card market in the period 2000-2005 are in line with the theoretical explanation of interchange fees as a balancing device in two-sided markets, the following stylized facts are of importance: (1) merchant service charges in the acquiring market decreased, (2) net annual cardholder fees in the issuing market increased, (3) the DMIF increased modestly.

At first glance these stylized facts seem not to be consistent with the balancing argument. Intuitively one would expect that decreasing merchant service charges in the acquiring market and increasing annual cardholder fees go hand in hand with a decreasing DMIF. However, as noted in section 2, the level of the social optimal interchange fee depends on demand, surplus created, cost structure and market power on the two sides of the market. In other words, the possibility that the stylized facts are the result of balancing considerations cannot $a$ priori be excluded. Therefore, to capture these interacting factors and to check whether the observed stylized facts are consistent with the balancing argument, a simple model for the derivation of the social optimal interchange fee in a payment card system is developed. Note that the results from the following analysis are not specific to this simple model but can for example as well be derived from the more general models mentioned in section $2 .{ }^{17}$ These models are however primarily designed to answer the question whether an unregulated payment

17 In fact, the model is only a "linear version" of a standard model of two-sided markets that is used by several authors. For an introduction to this standard model see Rochet (2003). 
platform will set the interchange fee systematically to high or to low compared to the social optimum. Contrary to the simplified model, they are however not particularly suited to comparative static analysis.

To keep things simple, it is assumed that there is a continuum of buyers (cardholders) and sellers (merchants). Buyers and sellers valuation of a payment card service $\left(v_{b}, v_{s}\right)$ are uniformly distributed on $[0, B]$ respectively $[0, S]$. The provision of a payment card service costs a total of $c$, where $c_{i}$ is incurred by the issuer and $c_{a}=c-c_{i}$ is incurred by the acquirer. Issuers charge price $p_{b}$ for the card service to buyers, while acquirers charge price $p_{s}$ to sellers. Buyers and sellers are drawn independently from their populations. If and only if $v_{s} \geq p_{s}$ and $v_{b} \geq p_{b}$ will they use the payment card service. The expected welfare $W^{e}$ from a random matching of buyers and sellers, given a price vector $\left[p_{b}, p_{s}\right]$, is therefore

$$
W^{e}=\left(v_{b}^{e}+v_{s}^{e}-c\right) \pi_{b} \pi_{s},
$$

where $\pi_{b}=\operatorname{prob}\left(v_{b} \geq p_{b}\right), \pi_{s}=\operatorname{prob}\left(v_{s} \geq p_{s}\right)$ and $v_{b}^{e}, v_{s}^{e}$ denotes the expected valuation of buyers and sellers. Due to the uniform distribution we have: ${ }^{18}$

$$
\pi_{b}=\frac{B-p_{b}}{B}, \pi_{s}=\frac{S-p_{s}}{S}, v_{b}^{e}=\frac{B+p_{b}}{2} \text { and } v_{s}^{e}=\frac{S+p_{s}}{2} .
$$

Equation (1) can thus be rewritten:

$$
W^{e}=\left[\frac{B+p_{b}}{2}+\frac{S+p_{s}}{2}-c\right] \frac{B-p_{b}}{B} \frac{S-p_{s}}{S} .
$$

Maximizing expected welfare $W^{e}$ under the condition that $p_{b}+p_{s} \geq c$ (i.e. the charged prices in the acquiring and the issuing market cover total costs of the provision of a payment card service) requires

$$
\frac{\partial W^{e}}{\partial p_{b}}=\frac{\partial W^{e}}{\partial p_{s}}
$$

18 To ensure that $0 \leq \pi_{b, s} \leq 1$ it is natural to assume that $\pi_{b, s}=0$ if $p_{b, s}>B, S$ and $\pi_{b, s}=1$ if $p_{b, s}<B, S$. 
The partial derivations of $W^{e}$ by $p_{b}$, $p_{s}$ are given by

$$
\begin{aligned}
& \frac{\partial W}{\partial p_{b}}=\frac{1}{2} \frac{\left(B-p_{b}\right)\left(S-p_{s}\right)}{B}-\frac{B-p_{b}}{B S}\left(\frac{B+p_{b}}{2}+\frac{S+p_{s}}{2}-c\right), \\
& \frac{\partial W}{\partial p_{s}}=\frac{1}{2} \frac{\left(B-p_{b}\right)\left(S-p_{s}\right)}{B}-\frac{S-p_{s}}{B S}\left(\frac{B+p_{b}}{2}+\frac{S+p_{s}}{2}-c\right) .
\end{aligned}
$$

This yields the following condition for the optimal price structure:

$$
p_{s}-p_{b}=S-B \text {. }
$$

In equilibrium the difference between the price charged by acquirers and issuers must equate the difference between sellers' and buyers' average valuation of a payment card service.

To allow for the possibility of imperfect competition, it is assumed that acquirers and issuers both can have some market power which is modelled as a constant margin $\left(m_{i}, m_{a} \geq 0\right)$. Obviously, when $m_{i}, m_{a}=0$ we are in a situation with perfect competition. With an interchange fee $f$ in the payment card system, prices charged by the acquirers and issuers are given by equations (5) and (6).

$$
\begin{aligned}
& p_{s}=c_{a}+m_{a}+f, \\
& p_{b}=c_{i}+m_{i}-f .
\end{aligned}
$$

From equation (4), (5) and (6) we can then deduce the optimal interchange fee $f^{*}$ in the model:

$$
f^{*}=\frac{1}{2}\left[S-B-c_{a}-m_{a}+c_{i}+m_{i}\right]
$$

It is easy to see from equation (7) that only if $S-B=c_{a}+m_{a}-c_{i}-m_{i}$ is the optimal price structure attainable with a zero interchange fee $\left(f^{*}=0\right)$. Further, whether the interchange fee is paid by the acquirer to the issuer or the other way round depends on the costs and margins of the acquirers and issuers as well as the valuation of card services of the buyers and sellers.

Considering the terms in the bracket of equation (7), three sources for a change of the interchange fee can be identified: first, the level of the interchange fee 
depends on the total valuation of credit card services of buyers and sellers $(B, S)$. Second, the level of the interchange fee is influenced by changes of the production costs $\left(c_{a}\right)$ and/or the market power $\left(m_{a}\right)$ of the acquirers. Finally, the level of the interchange fee depends on changes of the production costs $\left(c_{i}\right)$ and/or the market power $\left(m_{i}\right)$ of the issuers.

Given the above discussed stylized facts, it is now possible to analyse in the framework of the developed model whether the observed increase of the interchange fee can be alleged to the balancing argument. The model requires that, in case the increase of the interchange fee was the result of balancing (i.e. a reaction to changing market conditions), the three following conditions in the Swiss credit card market should have been simultaneously satisfied.

(i) Increased Valuation of Card Services of Buyers and Sellers: According to equation (4) the change of the price structure, i.e. the decrease in the merchant service charge and the increase in annual cardholder fees, implies a change in the total valuation of card services. If prices had remained unchanged in the considered period, an increase or a decrease of the interchange fee could only reflect a change in costs or market power on the issuing or acquiring side of the market. Thus, to explain the observed changes in the price structure in the Swiss credit card market, one should have observed a demand shock on the acquiring and/or the issuing side of the market in the considered period. More precise, the decrease in the merchant service charge and the increase in annual cardholder fees imply $\Delta\left[p_{s}-p_{b}\right]<0$ and therefore $\Delta[S-B]<0$. Unfortunately there is no information about such demand shocks available. However, one may argue that new trading channels, such as internet shopping, where procured services and goods are usually paid by credit card, indeed have increased the valuation of card services. For example, a larger increase of buyers than of seller's valuation of card services would be in line with the observed change in the price structure.

(ii) Decreasing Production Costs andlor Market Power in the Acquiring Market: Turning to equation (5), the observed decrease in the merchant service charge and the increase in the DMIF imply a decrease in the costs and/or the market power of the acquirers: $\Delta\left[c_{a}+m_{a}\right]<0$. Whether the market power of the acquirers increased or decreased in the considered period is ambiguous. The market exit of UBS Card Center increased the concentration in the acquiring market on the one hand substantially. On the other hand, the market entry of the two new German acquirers offering their services in Switzerland may have caused a decrease of the market power of the incumbent acquirers. Further, whether a technological or another shock reducing production costs occurred is questionable. In general, the acquiring business is characterized by relatively high fixed costs and economies of scale. Once the infrastructure is in place, the additional costs of processing 
another transaction are close to zero. According to the Swiss National Bank the number of transactions between 2000 and 2005 has risen by roughly $13 \% .{ }^{19}$ It can therefore not be excluded that production costs and/or market power in the acquiring business were indeed decreasing in the considered period.

(iii) Increasing Production Costs andlor Market Power in the Issuing Market: In the issuing business finally it was observed that the increase in the DMIF went along with an increase in annual cardholder fees. According to equation (6), this would imply an increase in the production costs and/or the market power in the issuing business: $\Delta\left[c_{i}+m_{i}\right]>0$. In the considered period, an increase of the market power of the issuers seems however very unlikely, since market shares remained constant and no market exits were observed. Equally, a supply shock increasing production costs is implausible. First, such a shock was not claimed by the issuers during the relevant period. Second, as mentioned before, due to an increased transaction volume and the existence of economies of scale, one would rather expect decreasing than increasing productions costs in the issuing business. A raise of the production costs and/or the market power in the issuing business seems therefore not a likely scenario.

In sum, the presented model suggests that even if the credit card industry is given "the benefit of the doubt" that between 2000 and 2005 a larger increase of buyers than of sellers valuation of credit card services occurred and production costs and/or market power in the acquiring business were decreasing, the developments in the issuing business hardly seem in line with the argument of an increase of the interchange fee (even if only a modest one) to balance the two sides of the market. According to the presented model, the observed price developments in the Swiss credit card market in the considered period seem therefore not to be the result of interchange fees used as a balancing device in a two-sided market. An alternative explanation for the observed developments is discussed in the following section.

19 Swiss National Bank, Monthly Statistical Bulletin (July 2006). The growth rate includes domestic and foreign card transactions. It seems however unlikely that all of the growth was due to foreign transactions. 


\section{Alternative Explanation for the Observed Developments}

One important aspect which models of two-sided markets usually do not capture - including the above presented model - is the fact that in reality the two sides of the market often are structurally not independent, i.e. these models neglect the ownership structure. In the credit card industry it is however common that an issuer and an acquirer are owned and controlled by the same financial institution. In Switzerland for example, the domestic Visa and MasterCard acquirers and issuers are largely owned by the same proprietors. In particular Telekurs Multipay, with a market share of $70-80 \%$, is a joint venture owned by the Swiss banks where UBS, Viseca and Credit Suisse (three out of the four issuers) hold the better part of the share capital. ${ }^{20}$ In fact, it is even usual that representatives of these issuers are members of the board of Telekurs Multipay. Furthermore, the only other domestic acquirer, Aduno (former Cornèr Banca), is a subsidiary of the issuer Viseca. Thus, the Swiss acquirers are basically owned and controlled by the issuing banks.

In such a constellation the incumbent issuing banks may use the multilateral agreed interchange fee as an anti-competitive device to protect profits in the credit card system and deter further market entry on the acquiring side, or to squeeze new aggressive competitors out of the acquiring market. To see this, recall that in the Swiss credit card market there is hardly any inter-brand competition between Visa and MasterCard. Further, the Visa and MasterCard credit card systems, holding a market share of $85-95 \%$, can be considered as dominant and price competition in the concentrated domestic issuing market was until the end of 2005 basically non-existent. As shown above, in Switzerland, the number of credit card transactions has steadily been rising in the last years. Thus, increasing the DMIF has as a first effect raised the revenues of the issuers. Due to the lack of price competition between the issuers and credit card brands, these increased revenues need however not to be passed on to the cardholders but simply increase industry profits.

So far, in the whole credit card system, this only amounts to profit-shifting from the acquiring side to the issuing side, i.e. the increase of the DMIF reduced the margin of the acquirers and increased the margin of the issuers. As discussed above, the reason for this "subsidy" to the issuers seems however not primarily to be to balance the two sides of the market. Rather, in such a situation an increase

20 Note that in 2008 the SIX Group was formed through the merger of the SWX Group, the SIS Group and Telekurs Group. The merger led to a reduction of the share capital of the three big domestic issuers (UBS, Credit Suisse and Viseca) in the Telekurs Group. 
in the DMIF may be used as a device to reduce incentives for market entry for foreign acquirers and to squeeze out new competitors of the market since it lessens their profit opportunities. To see this one has to be aware that, contrary to the acquiring market, the issuing business is basically of a national dimension. This is largely due to different national legislation concerning consumer credits, debt collection etc., which makes cross-border issuing an unattractive and risky business. Therefore, foreign issuers usually do not offer credit cards to Swiss residents. If they do, the acquisition of a credit card is normally connected with several inconveniences, such as substantial deposits for security in cash. Further, such credit cards are usually issued in a foreign currency (e.g. Euros or US Dollars) and each transaction in Swiss Francs implies an unfavorable exchange rate and a conversion fee. As a consequence, foreign companies only provide acquiring services in Switzerland. Thus, given a certain price level in the acquiring market, an increase in the interchange fee implies for the domestic players only a monetary transfer from one side of the system to the other, while for a new entrant in the acquiring market this money is lost for good. An increase of the DMIF consequently may protect profits of the incumbents in the credit card system and at the same time deter incentives for market entry of independent acquirers by raising their costs. ${ }^{21}$

Note that a three-party system with a central platform would not lead to the anti-competitive behavior described above for the domestic Visa and MasterCard business. In a three-party system the independent platform owner is only an intermediation service provider, i.e. he sets optimal charges on the two sides of the market to internalize network externalities. ${ }^{22}$ In contrast to a four-party system with cross-ownership, the platform owner in a three-party system has no incentive to set its charges such that competition is deterred in an anti-competitive way on either side of the market.

In fact, the investigation of the Swiss Competition Commission (ComCo) revealed that Swiss issuers and acquirers were well aware of the deterring and squeezing effect of raising interchange fees. In the minutes of the national card committees ComCo found the statement that the increase of the standard interchange fee of MasterCard was inter alia justified as a defense strategy against market entry from foreign acquirers. This suggests that the increase of the

21 Note that there is another way to deter incentives for market entry, namely decreasing the merchant service charge which also lowers the profit opportunities for foreign acquirers. This seems however an inferior strategy since decreasing the merchant service charge hurts not only the profits of the foreign acquirers but equally the ones of the incumbent players.

22 For a discussion of central platforms see e.g. Caillaud and Jullien (2003) or Armstrong (2006). 
interchange fee was primarily motivated by the market entry of the new aggressive acquirers and not by balancing arguments.

To conclude, the above analysis suggests that the balancing mechanism, a crucial assumption of the theory of two-sided markets, was not working properly in the Swiss credit card market in the considered period 2000-2005. The experience in Switzerland further shows that multilateral agreed interchanges fees have, depending on the specific market constellation, the potential to serve as a device for market entry deterrence and profit protection. A brief summary of how ComCo dealt with the problem of the multilateral agreed interchange fees is given in the next section.

\section{The Decision of ComCo}

As in several other countries, the interchange fees of Visa and MasterCard in Switzerland came under the scrutiny of the competition authority. ${ }^{23}$ ComCo opened an investigation on the matter in 2004 which ended in December 2005 with an amicable settlement between the parties and ComCo. Before discussing ComCo's decision and its effect on the market, it is interesting to note that the parties to the proceedings in Switzerland put little or no emphasis on the balancing argument. In particular, one party (Credit Suisse) denied explicitly that there is a connection between the level of the interchange fee and the cardholder fee. Rather, the parties claimed that interchange fees serve to compensate card issuers for the cost of services they supply to acquirers through the payment card scheme. It was also the parties who put forward the cost-based approach to interchange fees discussed below, which is another indication that the balancing argument was considered as unimportant by the incumbents of the Swiss credit card industry.

In its decision, ComCo came to the conclusion that the multilateral agreement on interchange fees constitutes a price-fixing agreement. In particular, the DMIF is the most important cost component for the acquirers, as it is an essential element - roughly $70 \%$ - of the merchant service charge. The level of the DMIF thus has a direct effect on the latitude available to the acquirers in setting prices. In practical terms, the interchange fee amounts to a minimum price in the acquiring business. However, ComCo was reluctant to prohibit the multilateral

23 An extensive discussion of interchange fee developments and regulations in various countries can be found in WeINER and Wright (2005). 
agreement on the DMIF since this would inevitably have resulted in bilateral negotiations between issuers and acquirers. ComCo accepted the argument that a system of multilateral negotiations on the DMIF might, for efficiency reasons, be superior to a bilateral system. In particular, in a bilateral system it cannot be excluded that due to the negotiation power of the issuers, the DMIF would be increased to an inefficient level. ${ }^{24}$ For these reasons, it was judged appropriate by ComCo to agree to an amicable settlement, i.e. to declare the positive commitments made by the parties binding. ${ }^{25}$

\subsection{The Amicable Settlement}

The amicable settlement provides for several measures intended to revive competition in the credit card market. The most important measure is the limitation of the DMIF to network costs. The amicable settlement puts the average DMIF applied by the issuers on an objective footing. ${ }^{26}$ Issuers no longer have the opportunity to take into account costs other than those that are purely network-related when setting the level of the DMIF. In accordance with the decision made, the effective network costs incurred by the issuers therefore constitutes an upper limit for the DMIF. The costs of services from which the cardholders benefit in the first place must not be taken into account in the calculation of the DMIF. Such costs include:

(i) Costs of funds (i.e. costs of the interest-free period until the cardholder is billed), since they are not directly related to the functioning of a payment system. Rather the interest-free period constitutes a service which is offered by the issuer to his customer on a bilateral basis. Merchants do indeed hardly benefit from this service unless one assumes that the interest-free period (normally 15-30 days) effectively increases consumption.

(ii) Costs of payment guarantee for credit write-offs which originate from financial commitments to which the cardholders cannot adhere to. These costs are entirely unrelated to the merchant, who is obliged to accept any credit card transaction authorized by the issuer. Only the issuer is in the position to assess the

24 For a discussion of multilateral vs. bilateral negotiated interchange fees, see SMALL and WRIGHT (2001).

25 This corresponds to the new rules in the EU, according to which the Commission may by decision make commitments that undertakings offer in order to meet the requirements of the Commission binding.

26 The concrete procedure chosen to determine the average DMIF can be found in the decision "Kreditkarten - Interchange Fee" of the Swiss Competition Commission (СомСо, 2006). It corresponds largely to the Australian approach (see Reserve Bank of Australia, 2002). 
creditworthiness of a cardholder. Allowing the issuer to shift the payment guarantee costs on the merchant creates a moral hazard problem: the issuer is incentivised to lower the creditworthiness requirements of his customers.

(iii) Costs of merchant marketing which should be borne directly, not via the interchange fee, by the merchant. This is to avoid cross-subsidization for specific marketing services primarily benefiting competitors and other merchants. Further, it seems reasonable that a merchant should have a say in the decision as to how much he would like to invest in marketing. While for some merchants the acceptance of credit cards may indeed be beneficial and business enhancing (e.g. a jeweller in an airport), other merchants consider credit cards rather as a cost driver, an unavoidable nuisance.

(iv) Costs of spend incentives which are targeted at the cardholders. Such spend incentives aim in the first place at motivating the cardholder to pay for his purchases with his credit card instead of using other means of payments. As in the case of merchant marketing, these spend incentives do not unambiguously benefit the merchants. Depending on the merchant service charge and the amount owed involved in the transaction, credit cards may constitute a comparatively expensive mean of payment for the merchant.

The ascertainment of the network costs is based on a precise definition of the cost elements that are allowed to be taken into account and is verified by a firm of auditors every three years. Note that this procedure inherently should create an incentive for cost reduction in the issuing business. The DMIF is calculated as a cost average over all issuers. Given different cost structures, this implies that some issuers will not be able to fully cover their costs with the current DMIF while others will earn a rent. By reducing their costs, the issuers can either achieve increased cost recovery or even expand their rent. The issuers had undertaken to make an initial reduction of the DMIF by roughly $15 \%$ after the decision came into force. Moreover, based on the ascertainment of network costs, the amicable settlement requires in the first three years a step-by-step reduction in the average DMIF from a current $1.65-1.7 \%$ to $1.3-1.35 \%$.

The amicable settlement comprises three additional measures. First, the abolition of the non-discrimination rule (NDR) which prohibits merchants who accept credit cards from imposing a surcharge on customers who pay by credit card or allowing a discount in return for payment in cash. ${ }^{27}$ Second, the acquirers

27 The NDR was already the subject of a decision of ComCo in 2002. Following an appeal against the decision the Competition Appeals Commission referred the case back to ComCo in 2005. The case was then pending before the Swiss Federal Supreme Court and closed shortly after the amicable settlement came into force. 
undertook in the amicable settlement to disclose to merchants on request the (sector-)relevant interchange fee rate. Third, the amicable settlement prohibits the exchange of issuer- and acquirer-specific market data and other sensitive information in the national card committees which was hitherto a standing practice. The approval of the amicable settlement has been limited by ComCo to a period of four years. This allows ComCo to re-examine the expected effects of the measures taken on competition in the credit card business at a later date on the basis of the new market conditions and to take account of developments abroad.

\subsection{Effects of the Amicable Settlement}

It is of course too early to assess in detail the effects of the amicable settlement in the credit card industry. So far, the decision seems however to have favourable effects on competition. In general, the Swiss credit card market has seen a continuous growth in the last four years. As Table 3 shows, the number of issued credit cards, the number of transactions as well as the transaction volume have steadily increased in Switzerland.

Table 3: Developments in the Swiss Credit Card Market

\begin{tabular}{lccc}
\hline & $\begin{array}{c}\text { Number of issued credit } \\
\text { cards (millions) }\end{array}$ & $\begin{array}{c}\text { Transaction volume in } \\
\text { CHF (billions) }\end{array}$ & $\begin{array}{c}\text { Number of transactions } \\
\text { (millions) }\end{array}$ \\
\hline 2000 & 3.13 & 14.62 & 74.7 \\
2001 & 3.28 & 15.51 & 80.4 \\
2002 & 3.33 & 15.34 & 81.7 \\
2003 & 3.36 & 14.76 & 81.7 \\
2004 & 3.39 & 14.96 & 82.0 \\
2005 & 3.45 & 15.84 & 84.3 \\
2006 & 3.87 & 17.21 & 90 \\
2007 & 4.31 & 19.87 & 106.6 \\
\hline
\end{tabular}

Source: Swiss National Bank, Monthly Statistical Bulletin

It needs to be mentioned that part of the observed growth since 2006 is due to the market entry of new issuers (GE Money, Jelmoli and Postfinance) and the introduction of new credit card products. Including co-branded products, nearly 150 different credit cards are issued in Switzerland today. Further, the variety of offered credit card conditions has widened substantially. For example, in the six 
months following ComCo`s decision, two large Swiss retail store chains (Migros and Coop) announced their intention to issue credit cards free of annual cardholder fees. These "free" credit cards are issued in cooperation with financial institutions who are licensees of Visa or MasterCard. The new variety of credit card also included commissions for cash withdrawals, interest rates for revolving credits etc. ${ }^{28}$ Incumbent issuers have reacted with new credit card products. UBS for instance has launched a "basic credit card" for CHF 40 per year.

These developments in the issuing market are remarkable. In particular, following the reduction of the DMIF in 2005 one would have expected low incentives for market entry in the issuing business. ${ }^{29}$ Whether there is a direct causality between these developments and ComCo's decision is therefore somewhat ambiguous. One interpretation of the developments is that ComCo's decision generally increased the awareness of the lack of competition in the issuing market and encouraged market entry from new issuers. Further, the observed market entries suggest that the reduction of the DMIF has not had any counterproductive effects so far. Even with lower earnings from the DMIF the new players seem to have estimated the potential profits sufficient to enter the market. In summary, the new market entrants have strongly revived competition in the issuing market, caused downward pressure on prices and forced the incumbent issuers to react with new products.

Developments in the acquiring business are also satisfactory. According to representatives of retail associations, acquirers passed on the decrease in the DMIF to the merchants in the form of lower merchant service charges. Thus, the retail associations seem to ascribe the decrease of the merchant service charges after 2005 to the decrease of the DMIF and not to more aggressive competition in the acquiring business. Total reduction of charges for the merchants are considerable. In 2007 for example, total transaction volume in Switzerland amounted to CHF 20 billion. Assuming again that roughly a quarter of all transactions involved a foreign credit card, total domestic transaction volume amounted to CHF 15 billion. Consequently, given a decrease of the DMIF of $0.35-0.4 \%$, total charges saved for the merchants amount to CHF 50-60 million. Whether these cost savings are passed on directly to the consumers, e.g. in the form of different

28 The variety of conditions has increased to an extend that today there seems even to be a market for supporting consumers in the choice of the best credit card product which depends on factors such as total turnover and number of transactions per month, number of domestic and foreign cash withdrawals per year, intended payments by instalments.

29 Note however, that no new foreign issuers entered the market: Postfinance and Jelmoli are domestic firms while GE Money is the traditional market leader in the Swiss consumer credit business. 
prices for credit card purchases, is however an unanswered question. Although the amicable settlement explicitly prohibits the non-discrimination rule, i.e. it allows price discrimination for purchases with credit cards, this practice does not yet prevail. In other words, most merchants still charge uniform prices today, independent of the mean of payment used in the transaction. It is therefore not realistic to assume that the cost savings of the merchants are instantly and fully passed on to the consumers.

\section{Summary and Conclusions}

In 2004, ComCo opened an investigation concerning the interchange fees of Visa and MasterCard in the Swiss credit card market which ended with an amicable settlement. The most important element of this settlement is the limitation of the interchange fee to the actual network costs of the issuers. In this paper it was discussed whether there was a market failure in the Swiss credit card market which justified ComCo's intervention and whether the remedies imposed in the amicable settlement eliminated the alleged market failure.

To this purpose a simple model to check whether interchange fees in the Swiss credit card market were used to balance the demand in the issuing and acquiring market as advocated by the theory of two-sided markets was presented. The results suggest that this most probably was not the case. An alternative explanation for the observed price developments in the acquiring and issuing market that points to anti-competitive effects of multilateral agreed interchange fees was then provided. In particular, there is some evidence that the multilateral agreed interchange fees served as a device to deter market entry of foreign acquirers and squeeze out new entrants of the market by raising rivals' costs.

In my opinion these results show that a cautious attitude from competition authorities towards multilateral agreed interchange fees, which are in their nature price-fixing agreements, is justified. When used strategically, multilateral agreed interchange fees may bear the potential for anti-competitive behavior. For Switzerland several important elements were identified which may help to turn multilateral agreed interchange fees into an anti-competitive measure. These are in particular interlocking ownership structures of the issuers and acquirers, foreclosed national issuing markets with no or weak price competition and the absence of inter-brand competition. These are elements which should be taken into consideration by competition authorities when investigating multilateral agreed interchange fees. Obviously, only if the investigation reveals a market failure, should an intervention be considered. 
In Switzerland, ComCo chose to agree to an amicable settlement which puts the applied DMIF on an objective footing. So far this settlement seems to have had predominantly positive effects in the market: the Swiss credit card market has seen continuous growth, new issuers with different credit card products entered the market and acquirers seem to have passed on the decrease of the DMIF to the merchants. Overall, the imposed remedies seem to have cured the "illness" in the credit card market more effectively than one could have had hoped for. To be sure, not all of the observed developments in the Swiss credit card market can directly be attributed to ComCo's decision. However, the case may be a good example of how a decision by a competition authority can have a signalling effect in a market and give a fresh impetus for more effective competition.

\section{References}

Armstrong, Mark (2006), "Competition in two-sided markets", Rand Journal of Economics, 37(3), pp. 668-691.

Baxter, Wiliam F. (1983), "Bank Interchange of Transactional Paper: Legal Perspectives", Journal of Law and Economics, 26, pp. 541-588.

Caillaud, Bernard and Bruno Jullien (2003), "Chicken \& egg: competition among intermediation service providers", Rand Journal of Economics, 34(2), pp. 309-328.

Carlton, Dennis W. and Alan S. Frankel (1995), "The Antitrust Economics of Payment Card Networks", Antitrust Law Journal, 63, pp. 643-668.

Chakravorti, Sujit (2003), "Theory of Credit Card Networks: A Survey of the Literature", Review of Network Economics, 2 (2), pp. 50-68.

СомСо (2006), "Kreditkarten - Interchange Fee", Recht und Politik des Wettbewerbs, 1, pp. 65-130 .

Evans, David S. (2003), "Some Empirical Aspects of Multi-sided Platform Industries", Review of Network Economics, 2 (3), pp. 191-209.

Frankel, Alan S. and Allan L. Shampine (2006), "The Economic Effects of Interchange Fees", Antitrust Law Journal, 73, pp. 627-673.

Gans, Joshua S. and Stephen P. King (2001), "The Role of Interchange Fees in Credit Card Associations: Competitive Analysis and Regulatory Issues", Australian Business Law Review, 29(1), pp. 94-122.

Hunt, Robert M. (2003), "An Introduction to the Economics of Payment Card Networks", Review of Network Economics, 2 (3), pp. 80-96.

Katz, Michael L. (2001), "Reform of Credit Card Schemes in Australia II: Commissioned Report”, Reserve Bank of Australia. 
Klein, Benjamin, Andreas V. Lerner, Kevin M. Murphy and Lacy L. Plache (2006), "Competition in Two-sided Markets: The Antitrust Economics of Payment Card Interchange Fees", Antitrust Law Journal, 73, pp. 571-626.

Reserve Bank of Australia (2002), "Reform of Credit Card Schemes in Australia - IV Final Reforms and Regulation Impact Statement 6", Reserve Bank of Australia.

Rochet, Jean-Charles and Jean Tirole (2002), "Cooperation Among Competitors: Some Economics of Credit Card Associations", Rand Journal of Economics, 33, pp. 549-570.

Rochet, Jean-Charles and Jean Tirole (2003), "An Economic Analysis of the Determination of Interchange Fees in Payment Card Systems", Review of Network Economics, 2 (2), pp. 69-79.

Rochet, Jean-Charles (2003), "The Theory of Interchange Fees: A Synthesis of Recent Contributions", Review of Network Economics, 2 (2), pp.79-124.

Rochet, Jean-Charles and Jean Tirole (2004a), "Two-sided Markets: An Overview", IDEI working paper.

Rochet, Jean-Charles and Jean Tirole (2004b), "Defining Two-sided Markets", IDEI working paper.

Roson, Roberto (2005), "Two-Sided Markets: A Tentative Survey", Review of Network Economics, 4 (2), pp. 142-160.

Schmalensee, Richard (2002), "Payment Systems and Interchange Fees", Journal of Industrial Economics, 50, pp. 103-122.

SMALl, John and Julian WRight (2001), "The bilateral negotiation of Interchange Fees in Payment Schemes", mimeo, NECG and University of Auckland.

Weiner, Stuart E. and Julian Wright (2005), "Interchange Fees in Various Countries: Developments and Determinants", Review of Network Economics, 4 (4), pp. 290-323.

Wright, Julian (2003), "Optimal Card Payment Systems", European Economic Review, 47, pp. 587-612.

Wright, Julian (2004a), "The Determinants of Optimal Interchange Fees in Payment Systems", Journal of Industrial Economics, 52, pp. 1-26.

Wright Julian (2004b), "One-sided logic in Two-sided Markets", Review of Network Economics, 3 (1), pp. 42-63. 


\section{SUMMARY}

In 2004 the Swiss Competition Commission (ComCo) opened an investigation concerning multilateral agreed interchange fees in the Swiss credit card market which ended with an amicable settlement. The most important element of this amicable settlement consists in the limitation of the interchange fee to the actual network costs of the issuers. In this paper I discuss whether there was a market failure in the Swiss credit card market which justified the intervention by ComCo and whether the remedies imposed in the amicable settlement eliminated the alleged market failure. 